\title{
Aura in temporal lobe epilepsy: clinical and electroencephalographic correlation
}

\author{
AK GUPTA, PM JEAVONS, RC HUGHES, A COVANIS \\ From Dudley Road Hospital, Birmingham, New Cross Hospital, Wolverhampton and the Clinical \\ Neurophysiology Unit, University of Aston, Birmingham, UK
}

SUMMARY Patients with temporal lobe epilepsy were evaluated for their aura and the site of EEG abnormality. Autonomic and psychic auras were more frequently associated with right-sided temporal lobe lesions in 290 patients.

Several reports in the literature have emphasised the importance of the aura in the clinical diagnosis of temporal lobe epilepsy. Gowers ${ }^{1}$ and Lennox and $\mathrm{Cobb}^{2}$ reported that more than $50 \%$ of their patients had an aura, the most common being abdominal in origin. Similar observations have also been made by other workers. ${ }^{3-6}$ Recently, there have been reports where the temporal lobe lesion has been associated with ictal water drinking behaviour, ${ }^{7}$ psychoses, ${ }^{8-13}$ neuroses, ${ }^{1415}$ hypergraphia, ${ }^{16}$ memory and language impairment. ${ }^{17-19}$ Other reports have failed to demonstrate any correlation between the site of the temporal lobe lesion and the symptomatology of temporal lobe epilepsy. ${ }^{20-22}$ Most of these reports have been either observations based on a psychiatric population or isolated cases. Furthermore, none of these studies have correlated the type of aura with the lateralisation or localisation of the electroencephalographic abnormality. The present communication describes the types of auras seen in patients with temporal lobe epilepsy and their correlation with the site of the EEG abnormality.

\section{Patients and methods}

Evaluation of the aura in relation to the site of the EEG abnormality has been made in 290 patients with complex partial seizures. They all had attended the Epilepsy Clinic or Neurology Clinic between the years 1978-1981 and were seen by one of us. Each patient had a detailed clinical and neurological examination at the time of the first visit.

Address for reprint requests: Dr AK Gupta, EEG Department, Dudley Road Hospital, Birmingham B18 7QH, UK.

Received 20 January 1983 and in revised form 15 July 1983. Accepted 2 August 1983
The clinical case notes were later reviewed by one of us (AKG).

Auras were grouped according to the guidelines recommended by the Commission of the International League Against Epilepsy. ${ }^{23}$ There were 154 females and 136 males and the age range was 12-67 years. Most patients had a long history of epilepsy, the mean duration being 13.5 years. EEGs were taken on 16 channel machines using the International 10/20 electrode placement system, and the records were examined visually. The lateralisation of EEG abnormalities was based on the finding of localised spikes, sharp waves, or slow waves, alone or in combination.

\section{Results}

Details of the aura and the lateralisation of the EEG abnormality in the 290 patients are shown in table 1 . The EEG abnormality was clearly lateralised in 250 patients, being right-sided in $56 \%$ and left-sided in $44 \%$. Of the 140 patients with right-sided abnormality, $36 \%$ had a psychic aura, $34 \%$ an autonomic aura, $16 \%$ a sensory aura, $1 \%$ a motor aura and $13 \%$ did not have an aura. Of the 110 patients with left temporal abnormality, the aura was motor in $14 \%$, psychic in $10 \%$, sensory in $10 \%$, autonomic in $8 \%$ and there was no aura in $58 \%$. In $105(36 \%)$ patients there was no aura and of these 105 , the EEG abnormality was most commonly on the left $(61 \%)$, less common on the right $(17 \%)$ and $10 \%$ had bilateral abnormality. The EEG was normal in $12 \%$.

\section{Discussion}

According to the commission on classification and terminology of the International League Against Epilepsy 23 "aura is that portion of the seizure which occurs before consciousness is lost and for which memory is retained afterwards. It may be that, as in 
Table 1 Distribution of aura related to EE G lateralisation

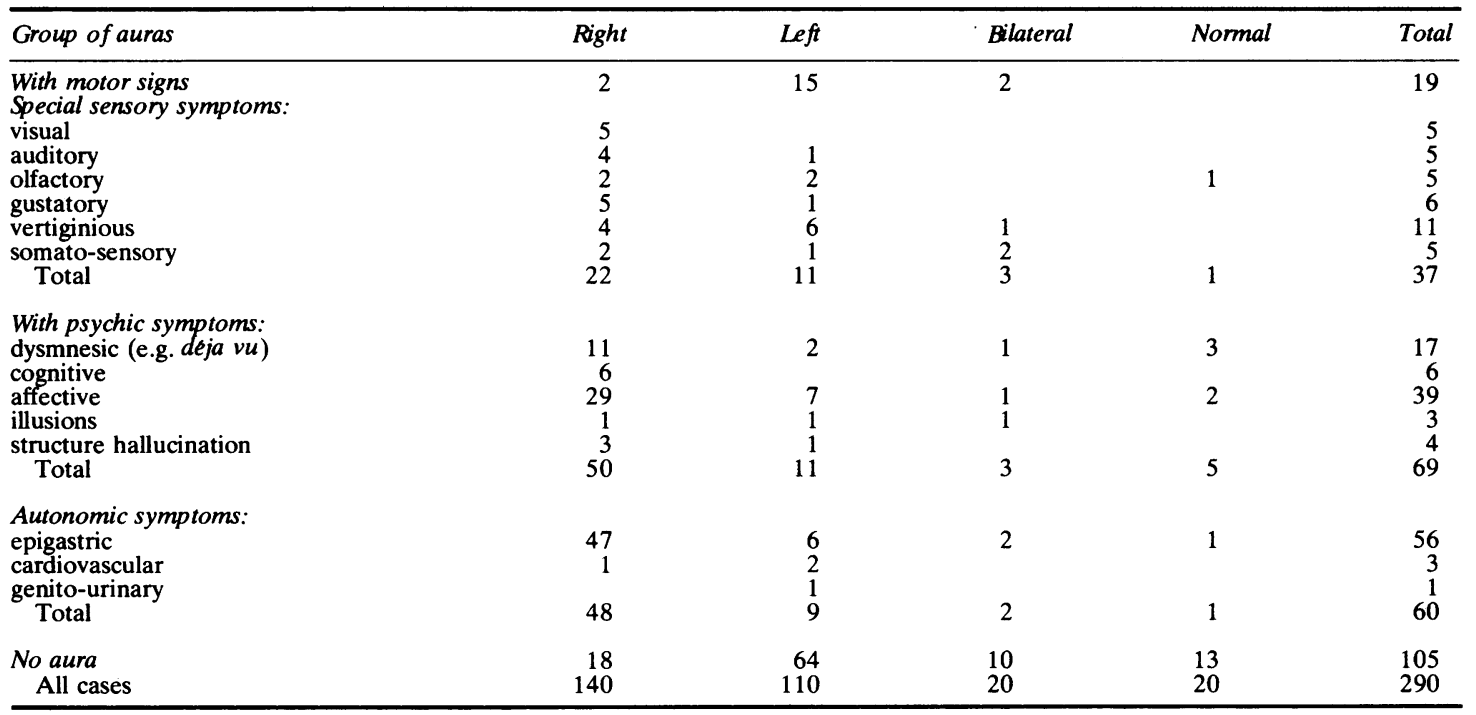

simple partial seizures, the aura is the whole seizure. When consciousness is subsequently lost, the aura is in fact the signal symptom of a complex partial seizure". Using this guideline, we found that $64 \%$ of our patients had a definite aura. Gowers, in 1901, reported an incidence of $57 \% .^{1}$ Lennox and $\mathrm{Cobb}^{2}$ found an aura in 764 patients out of 1527 cases $(56 \%)$, practically the same percentage as Gowers. Currie $e t a l^{6}$ reported a similar incidence of aura in cases of temporal lobe epilepsy. A slight variation in the percentage of auras in temporal lobe epilepsy reported by other workers and ours may be due to different criteria used for the diagnosis of temporal lobe epilepsy, and the type of sample used for the study of aura. Lennox and $\mathrm{Cobb}^{2}$ studied aura in 1359 non-institutional patients having seizures as a presenting symptom. Currie et $a l^{6}$ drew patients from different sources and they used different criteria in the diagnosis and classification of a seizure and its components.

There have been conflicting views on the question of hemispheric preference of EEG abnormalities in epileptic patients. Earlier studies have indicated a left preponderance of EEG abnormality in various neurological and psychiatric disorders. Obrist and Henry ${ }^{24}$ found a high preponderance of slow waves on the left side in EEGs of aged psychiatric patients. A similar observation in different neurological disorders was also made by Hughes ${ }^{25}$ and in cases of vascular disturbances by Earle et al. ${ }^{26}$ AjmoneMarsan and Ralston ${ }^{27}$ reported that $90 \%$ of patients with bitemporal epilepsy showed the initial seizure discharges on the left during metrazol activation.
Mani et $a l^{28}$ reported a significant preponderance of left temporal lobe foci in temporal lobe epilepsy. Their observations, based upon 248 patients, showed that $48 \%$ had a left EEG focus, in $31 \%$ it was on the right and in $21 \%$ it was bilateral.

Currie et $a l^{6}$ surveyed the clinical course and prognosis of temporal lobe epilepsy in 666 patients and found a significant preponderance of left-sided EEG abnormality. However, their sample indicates that 169 patients had various types of neurological disórders, the most common being tumour, head injury, gliosis and cerebrovascular disorders. Many investigators have claimed a left-sided preference for thrombi, emboli and aneurysm because of a presumed more direct blood flow from the aorta to the left carotid artery. We did not find any left preponderance in our sample of temporal lobe epilepsy. Of the 250 patients with a clear EEG lateralisation, $56 \%$ had a focus in the right temporal lobe and $44 \%$ in the left. There have been a few reports where workers have noticed a slight preponderance of all types of EEG abnormalities on the right, particularly in the posterior temporal and occipital regions. This was more so if the abnormality consisted of a slow wave asymmetry. ${ }^{29} 30$

Amongst the different types of auras as listed in tables 1,2 , we found a significantly greater preponderance of aura referable to the epigastrium (55 of the 59 autonomic aura). This observation agrees well with the findings of earlier workers. $^{1-631}$ Epigastric aura has often been described either as a "butterfly sensation" or as "unpleasant sensation" which moves up into the throat. The exact mechan- 
Table 2 Distribution of groups of aura in patients with temporal lobe epilepsy and site of EEG abnormality

\begin{tabular}{lclc}
\hline Type of aura & Right $^{*}$ & Left $^{*}$ & Bilateral \\
\hline Motor & 2 & 15 & 2 \\
Sensory & 22 & 11 & 3 \\
Psychic & 50 & 11 & 11 \\
Autonomic & $48 \dagger$ & $9 \dagger$ & $2 \dagger$ \\
$\quad$ Total & 122 & 46 & 18 \\
\hline
\end{tabular}

${ }^{*} \chi^{2}=38.7, \mathrm{p}<0.001$.

tEpigastric $47,6,2$ respectively.

ism and precise cerebral localisation is still uncertain. Earlier studies have suggested that frontotemporal portion of the limbic system plays a fundamental role in the expression of visceral and emotional activity. ${ }^{31-33}$

Van Buren ${ }^{5}$ observed a sensation closely resembling abdominal aura in eight epileptic and six nonepileptic patients on stimulating the mesial temporal region and basal ganglia. In the series published by Van Buren and Ajmone-Marsan, ${ }^{34}$ out of eight subjects with epigastric aura, five had a definite abnormality in the right temporal lobe and in three either the abnormality was bilateral or with slight preponderance in the left temporal lobe. A similar preponderance of a right temporal lobe foci and abdominal aura is also evident in the report published by Remillard et al..$^{7}$ It is surprising that this association was not discussed by these authors.

In the present study, we found that out of 60 patients with an autonomic aura this was epigastric in 56. Of these 56, 47 had definite EEG abnormality in the right temporal lobe and only six had an abnormality in the left temporal lobe and in two cases the abnormality was bilateral (table 1). One patient had a normal EEG. A comprehensive explanation of this association between the right temporal lobe lesion and epigastric aura seems beyond our grasp at the moment. However, our data certainly reflect a possibility that the right hemisphere might have a significant role in the expression of this type of aura in cases of temporal lobe epilepsy.

Penfield and Perot ${ }^{35}$ reported that various types of "experiential" responses were more likely to be elicited from right rather than left temporal stimulation. However, Gloor $e^{t}$ al $^{36}$ failed to confirm their observations, but did report a significant association of fear with an unpleasant visceral sensation in the abdomen. Our study in part agrees with the observations of Penfield and Perot ${ }^{35}$ as the majority of our subjects with auras had abnormality in the right temporal lobe rather than in the left.

The second most common type of aura in our patients was a psychic one, most patients in this group presenting either with an aura of déja $v u$ or an affective component. Analysing their EEGs we found a significantly higher incidence of abnormality in the right temporal lobe (table 1). This supports the hypothesis of earlier workers that the individual with a right temporal lobe lesion is more prone to develop a disorder related to affect or emotion. Flor-Henry ${ }^{89}$ reported that psychotic depression tended to occur in patients with a right temporal lobe lesion. Gainotti, ${ }^{37}$ in a study based upon patients with brain damage to the non-dominant hemisphere, observed a tendency to disinhibition, indifference and elation. Other workers have also noted a disturbance of mood, emotion and behaviour. ${ }^{91038}$ Penfield and Perot $^{35}$ reported the presence of an aura of déja $v u$ in a patient on stimulating the non-dominant hemisphere.

Slater and Beard ${ }^{39}$ found a high preponderance of schizophreniform psychosis in association with temporal lobe epilepsy. Monukhine and Dinabourg ${ }^{40}$ reported that epileptic children with a left sided temporal lobe lesion showed more behaviour disturbances than those who had abnormality in the right temporal lobe. A similar view in subjects with organic brain damage was expressed by Lishman. ${ }^{41}$ Shukla and Katiyar ${ }^{15}$ looked at the relationship between psychotic disorders and sites of temporal lobe EEG abnormality. They found a significant relationship between neurotics and the right temporal lobe EEG focus but no significant lateralising effect on other diagnostic categories of psychotic disorders. Falconer and Taylor ${ }^{14}$ also found neurotics to have more dysfunction in the non-dominant hemisphere. A similar conclusion also emerged from the data reported by Taylor. ${ }^{10}$

Recent studies have indicated a significant role of limbic and/or temporal neo-cortical activation in the genesis of various kinds of "experiential" responses which occurred in patients of temporal lobe epilepsy. ${ }^{35} 36$

In the present study we failed to observe any symptoms suggestive of florid-psychosis or schizophreniform reaction. This is not surprising since our data are based upon subjects who have complex partial epilepsy without any apparent psychiatric disorders. However, our results do indicate that the right temporal lobe has a significant influence in the control of autonomic and psychic functions, particularly visceral and affective in nature. Thus, in part, our study supports the views of previous work$\mathrm{ers}^{8-10141538}$ who attempted to correlate neuroses and affective disorders with a right temporal lobe lesion. Our findings may also assist the clinician in correlating the symptomatology of temporal lobe epilepsy to the site of temporal lobe involvement as well as in understanding psycho-pathology of certain psychiatric disorders which sometimes co-exist with complex partial epilepsy. 
We are grateful to our colleagues for referring patients to the Epilepsy Clinic. We appreciate the skill of our technicians who have carried out all the EEG investigations at Dudley Road and New Cross Hospitals.

\section{References}

${ }^{1}$ Gowers WR. Epilepsy and Other Chronic Convulsive Diseases; their Causes, Symptoms and Treatment. London: Churchill, 1901:320.

${ }^{2}$ Lennox WG, Cobb S. Epilepsy XIII. Aura in epilepsy: A statistical review of 1359 cases. Arch Neurol 1933;30:374-87.

${ }^{3}$ Falconer MA, Cavanagh JB. Clinico-pathological consideration of temporal lobe epilepsy due to small focal lesions. Brain 1959;82:483-4.

${ }^{4}$ Jasper HH, Rasmussen T. Studies of clinical and electrical responses to deep temporal stimulation in man with some considerations of functional anatomy. Res Publ Ass Res Nerv Ment Dis 1958;36:316-34.

5 Van Buren JM. The abdominal aura: A study of abdominal sensations occurring in epilepsy and produced by depth stimulator. Electroencephalogr Clin Neurophysicl 1963;15:1-19.

${ }^{6}$ Currie S, Heathfield WG, Henson RA, Scott DF. Clinical course and prognosis of temporal lobe epilepsy-a survey of 666 patients. Brain 1971;94:173-90.

${ }^{7}$ Remillard GM, Andermann F, Gloor P, Oliver A, Martin JB. Water-drinking as ictal behaviour in complex partial seizures. Neurology (NY) 1981;31:117-24.

${ }^{8}$ Flor-Henry P. Psychoses and temporal lobe epilepsy: A controlled investigation. Epilepsia 1969;10:363-95.

${ }^{9}$ Flor-Henry P. Schizophrenic-like reactions and affective psychoses associated with temporal lobe epilepsy: Aetiological factors. Am J Psychiatry 1969;126:4004.

${ }^{10}$ Taylor DC. Mental state and temporal lobe epilepsy-A correlative account of 100 patients treated surgically. Epilepsia 1972;13:727-65.

" Flor-Henry P. Epilepsy and Psychopathology. In: Granville Grossman K, ed. Recent Advances in Clinical Fsychiatry;' Vol 2. Edinburgh: Churchill Livingstone, 1976.

${ }^{12}$ Sherwin I. Psychosis associated with epilepsy: significance of the laterality of the epileptogenic lesion. J Neurol Neurosurg Psychiatry 1981;44:83-5.

${ }^{13}$ Levin DN, Finklestein S. Delayed psychosis after right temporo-parietal stroke or trauma: Relation to epilepsy. Neurology (NY) 1982;32:267-73.

${ }^{14}$ Falconer MA, Taylor DC. Temporal lobe epilepsy: clinical features, pathology, diagnosis and treatment. In: Price JH, ed. Modern Trends in Psychological Medicine. Vol 2. London: Butterworths, 1970:34673.

is Shukla GD, Katiyar BC. Psychiatric disorders in temporal lobe epilepsy: the laterality effect. $\mathrm{Br} J$ Psychiatry 1980;137:181-2.

${ }^{16}$ Roberts JKA, Robertson MM, Trimble MR. The lateralising significance of hypergraphia in temporal lobe epilepsy. J Neurol Neurosurg Psychiatry 1982;45:131-8.
${ }^{17}$ Milner B. Disorders of learning and memory after temporal lobe lesions in man. Clin Neurosurg 1971;19:421-46.

${ }^{18}$ Glowinski H. Cognitive deficits in temporal lobe epilepsy. J Nerv Ment Dis 1973;157:129-37.

${ }^{19}$ Mayeux R, Brandt J, Rosen J, Benson F. Interictal memory and language impairment in temporal lobe epilepsy. Neurology (Minneap) 1980;30:120-5.

${ }^{20}$ Bear DM, Fedio P. Quantitative analysis of interictal behaviour in temporal lobe epilepsy. Arch Neurol 1977;34:454-67.

${ }^{21}$ Kristensen O, Sindroup EH. Psychomotor epilepsy and psychosis: II. Electroencephalographic findings (sphenoidal electrode recordings). Acta Neurol Scand 1978;57:370-9.

22 Jenson I, Larsen JK. Mental aspects of temporal lobe epilepsy; follow-up of 74 patients after resection of a temporal lobe. J Neurol Neurosurg Psychiatry 1979;42:256-65.

${ }^{23}$ Commission on classification and terminology of the International League Against Epilepsy. Proposal for revised clinical electroencephalographic classification of epileptic seizures. Epilepsia 1981;22:489-501.

${ }^{24}$ Obrist WD, Henry CE. EEG findings in aged psychiatric patients. J Nerv Ment Dis 1958;126:254-67.

${ }^{25}$ Hughes JR. A statistical analysis on the location of EEG abnormalities. Electroencephalogr Clin Neurophysiol 1960;12:905-9.

${ }^{26}$ Earle KM, Baldwin M, Penfield W. Incisural sclerosis and temporal lobe seizures produced by hippocampal herniation at birth. Arch Neurol 1953;69:27-37.

${ }^{27}$ Ajmone-Marsan C, Ralston B. In: The Epileptic Seizure: lts Functional Morphology and Diagnostic Significance. Springfield, Illinois: Charles C Thomas, 1957:228.

${ }^{28}$ Mani KS, Mani AJ, Ramesh CK, Subba Krishna DK Kaliaperumal VG. In: Proceedings of the National Seminar on Epilepsy, Bangalore, India. 1975:56-60.

${ }^{29}$ Cohn $R$. On the significance of bioccipital slow wave activity in the electroencephalograms of children. Electroencephalogr Clin Neurophysiol 1959;11:63756.

${ }^{30}$ Aird RB, Gastaut Y. Occipital and posterior electroencephalographic rhythm. Electroencephalogr Clin Neurophysiol 1959;11:637-56.

${ }^{31}$ Maclean PD, Alejandro P, Arellano Z. Basal lead studies in epileptic automatisms. Electroencephalogr Clin Neurophysiol 1950;2:1-16.

${ }^{32}$ Maclean PD. Some psychiatric implications of physiological studies on fronto-temporal portion of limbic system (visceral brain). Electroencephalogr Clin Neurophysiol 1952;4:407-18.

${ }^{33}$ Maclean PD, Delgado JMR. Electrical and chemical stimulation of fronto-temporal portion of limbic system in the waking animal. Electroencephalogr Clin Neurophysiol 1953;5:91-100.

${ }^{34}$ Van Buren JM, Ajmone-Marsan C. A correlation of autonomic and EEG components in temporal lobe epilepsy. Arch Neurol 1960;3:683-93.

${ }^{35}$ Penfield W, Perot $P$. The brain's record of auditory and visual experience. A final summary and discussion. Brain 1963;86:595-696. 
${ }^{36}$ Gloor P, Oliver A, Quesney LF, Andermann F, Horowitz $\mathrm{S}$. The role of the limbic system in experiential phenomena of temporal lobe epilepsy. Ann Neurol 1982;12:129-44.

${ }^{37}$ Gainotti G. Emotional behaviour and the hemispheric side of the lesion. Cortex 1972;5:41-55.

${ }^{38}$ Gregoriadis A, Fragos E, Kapslakis Z, Mandouvalos B. In: Vth world Congress of Psychiatry. Mexico: Prenisa Media Mexicana, 1971:325.
${ }^{39}$ Slater E, Beard AW. The schizophrenia-like psychoses of epilepsy. Br J Psychiatry 1963;95:95-150.

${ }^{40}$ Mnoukhine SS, Dinabourg EY. Epileptiform manifestations in early right and left-sided lesions in the brain in children. Zhurnal Nevropatalogii Psikhiatrii, Korsakov 1965;65:1073-7.

${ }^{41}$ Lishman WA. Brain damage in relation to psychiatric disability after head injury. $B r \quad J$ Psychiatry 1968;114:373-410. 